\title{
Esclavage, métissage, liberté. La Révolution française en Guadeloupe. 1789-1802
}

\section{Bernard Gainot}

\section{(2) OpenEdition \\ 1 Journals}

\section{Édition électronique}

URL : https://journals.openedition.org/ahrf/2023

DOI : 10.4000/ahrf.2023

ISSN : 1952-403X

Éditeur :

Armand Colin, Société des études robespierristes

\section{Édition imprimée}

Date de publication : 1 juin 2005

Pagination : 193-195

ISSN : 0003-4436

\section{Référence électronique}

Bernard Gainot, «Esclavage, métissage, liberté. La Révolution française en Guadeloupe. 1789-1802 », Annales historiques de la Révolution française [En ligne], 340 | avril-juin 2005, mis en ligne le 20 avril 2006, consulté le 23 avril 2022. URL : http://journals.openedition.org/ahrf/2023 ; DOI : https://doi.org/ 10.4000/ahrf.2023

Ce document a été généré automatiquement le 23 avril 2022.

Tous droits réservés 


\title{
Esclavage, métissage, liberté. La Révolution française en Guadeloupe. 1789-1802
}

\author{
Bernard Gainot
}

\section{RÉFÉRENCE}

Frédéric RÉGENT, Esclavage, métissage, liberté. La Révolution française en Guadeloupe.

1789-1802, Paris, Grasset, 2004, 484 p., ISBN 2-246-64481, $22 €$.

1 Cet ouvrage est réalisé à partir de la thèse remarquable de l'auteur, soutenue à l'Université Paris I, sous le titre suivant: Entre esclavage et liberté; esclaves, libres et citoyens de couleur en Guadeloupe, une population en révolution (1789-1802). Il est toutefois le produit d'une réécriture, de façon à rendre accessible au plus large public le fruit de recherches approfondies dans un grand nombre de dépôts d'archives, notamment à la Guadeloupe (il faut souligner tout particulièrement la judicieuse exploitation des minutes notariales) et au Centre des archives d'outre-mer à Aix-en-Provence.

2 Le propos est de mettre en perspective l'événement révolutionnaire en Guadeloupe ; pour cela, la période révolutionnaire en elle-même n'occupe que la moitié de l'ouvrage. L'auteur commence par faire un tableau de la société coloniale à la fin du XVIIIe siècle. Une société entièrement dominée par le mode de production esclavagiste (les esclaves représentent $85 \%$ de la population dans une économie massivement investie dans la plantation sucrière). Tous les aspects du monde servile sont passés en revue, pour présenter un tableau très finement diversifié d'une hiérarchie des situations (domestiques, ouvriers et artisans, "nègres de culture", conditions urbaines et rurales), des cultures (africaines et en voie de créolisation) et des couleurs. Le groupe dominant sait habilement tirer partie de cette diversification, jouer des oppositions d'intérêts et de la cascade du mépris, si importante dans cette société qui repose sur le profit immédiat, mais aussi sur la culture des apparences ; hors de cette stratification, 
on ne comprend pas comment une infime minorité peut maintenir une si écrasante majorité dans la servitude. La condition servile est toutefois globalement mortifère ; châtiments corporels, sous-alimentation, maladies, sont un lourd tribut à payer à la colonisation sucrière.

C'est toutefois le préjugé de couleur qui apparaît comme le fait structurant des sociétés antillaises. Un fait de plus en plus affirmé à la veille de la Révolution, et dont sont particulièrement victimes les libres de couleur, catégorie sociale en pleine ascension, par son dynamisme économique, par son importance croissante dans la propriété (y compris la propriété des esclaves), par son rôle dans le maintien de l'ordre, dans la culture et la sociabilité (tout particulièrement la sociabilité urbaine.)

La Révolution lève le couvercle, pour donner libre cours à l'expression de toutes ces contradictions, pour libérer ce mélange détonant fait de l'accumulation de la peur, des rancœurs et des espérances. La caste blanche se déchire, au gré des oppositions locales (Basse-Terre contre Pointe-à-Pitre) et des alignements politiques (patriotes contre "royalistes»). La rhétorique révolutionnaire est omniprésente, mais souvent trompeuse lorsqu'elle est transposée aux Antilles, où la liberté sert de masque à la défense des privilèges. Mais les populations de couleur mettent rapidement cette rhétorique au service de leurs propres revendications. Des révoltes partielles d'esclaves, certaines d'entre elles faisant l'objet d'analyses inédites, servent de contrepoint aux luttes politiques qui paraissent circonscrites à la population blanche. Bien vite, les libres de couleur entrent en scène, mais sur un mode ambigu, dans une position subordonnée aux luttes qui déchirent la fraction dirigeante; consolidation d'un front des propriétaires pour le maintien du mode de production esclavagiste, ou ralliement aux petits blancs républicains, dans l'espoir d'une reconnaissance de l'égalité des droits politiques? Progressivement, c'est cette dernière ligne qui l'emporte.

5 La guerre, puis le décret d'abolition de pluviôse an II (la liberté générale) bouleversent la donne; en ouvrant la colonie aux Anglais dans un premier temps, en permettant sa reconquête par les républicains alliés aux anciens esclaves, à partir de juin 1794. Se place alors l'une des analyses les plus novatrices de l'ouvrage. Frédéric Régent apporte des perspectives tout à fait intéressantes sur la société guadeloupéenne sous le Directoire, puis sur la période de la restauration coloniale de 1802-1803. L'investigation des registres d'état-civil, des fonds notariaux, des circulaires administratives, montre que la période est véritablement porteuse de changements des conditions d'existence pour l'ensemble de la population. Les regroupements par castes font place à des changements plus subtils, et d'apparence plus égalitaire. Les séquestres sur les biens des émigrés et des suspects entraînent une redistribution des propriétés. Sans toutefois que le cadre général de la plantation soit affecté, ce qui est une donnée majeure de toutes les économies des Antilles révolutionnées; les anciens esclaves, devenus "cultivateurs", sont soumis à des règlements de culture contraignants. Ils sont " attachés » aux habitations, mais perçoivent théoriquement une partie des revenus sous forme de salaire.

À première vue, le changement est insignifiant; une analyse plus fine de la réalité montre qu'une certaine amélioration des conditions de vie a pu se faire jour. Le travail reste dur, mais les recours existent contre les châtiments corporels. La mortalité est en léger recul. Et, surtout, les contraintes administratives peuvent être tournées, les 
enrôlements dans l'armée coloniale ou sur les équipages corsaires sont nombreux, les fuites vers les villes où existent de réelles possibilités de promotion, sont nombreuses.

6 Les relations entre les couleurs sont moins rigides; en attestent les cas de mariages inter-ethniques, certes peu nombreux, mais significatifs. Ils ne sont plus l'exception honteuse, que l'ancienne société coloniale stigmatisait.

7 Sous le régime autoritaire de Victor Hugues, les blancs républicains continuent de dominer l'économie et l'administration. Mais, progressivement, les anciens libres de couleur (rebaptisés "libres d'avant le décret" ou "rouges", car majoritairement mulâtres) s'affirment, grâce à l'amalgame militaire, grâce aux profits tirés de la guerre de course, grâce au dynamisme urbain, qui contraste avec la stagnation de l'économie de plantation. Les conclusions de Frédéric Régent sur les nouvelles dynamiques monétaires, urbaines, maritimes, essentiellement profitables aux anciens libres de couleur, confirment les études menées par Anne Pérotin-Dumon sur Basse-Terre et Pointe-à-Pitre, dans son récent ouvrage, la ville aux îles, la ville dans l'île, dont il a été rendu compte dans les colonnes de cette revue.

Après le rappel de Victor Hugues en métropole, se réalise une véritable « révolution de la couleur ", essentiellement sous l'impulsion de ce groupe - on peut dire de cette classe sociale - qui affirme sa vocation hégémonique. Les officiers de couleur s'opposent à la tentative de reprise en main métropolitaine menée par le capitaine général Lacrosse. Mais c'est une révolution avortée; d'abord en raison des tensions entre les officiers. Magloire Pélage, éphémère gouverneur, cherche constamment le compromis avec Lacrosse, tandis que les plus radicaux (Delgrès, Ignace) préparent une résistance vouée à l'échec, du fait de la passivité des cultivateurs, peu enclins à soutenir des militaires qui se sont constamment opposés, y compris par la répression de leurs mouvements, à leurs revendications. Au passage, l'auteur fait, à bon droit, justice d'une légende tenace. L'objectif des militaires de couleur, toutes tendances confondues, n'est pas la rupture avec la métropole. Les plus radicaux, Delgrès en tête, ne sont pas les derniers à faire appel à Bonaparte qu'ils pensent favorable à leur cause lorsqu'il aura été véritablement informé de leurs motivations réelles. Épuisée par les divisions, l'isolement et les illusions, la "révolution de la couleur» échoue; Lacrosse peut procéder au désarmement des troupes, objectif prioritaire, préalable indispensable au progressif rétablissement de l'esclavage, affirmé en 1803.

Cette minutieuse étude, qui croise l'histoire politique et l'histoire sociale, est une contribution majeure à la connaissance du fait révolutionnaire dans les Antilles. C'est aussi un ouvrage de référence, dont la connaissance est indispensable au traitement de l'actuelle question d'Histoire moderne mise au concours de recrutement des enseignants (pour 2005 et 2006). 